Мартыненко Елена Викторовна

доктор политических наук, профессор, заведующая кафедрой теории и истории журналистики филологического факультета Российского университета дружбы народов

\section{ОБЩЕСТВЕННЫЕ ОРГАНИЗАЦИИ В СИСТЕМЕ СОЦИАЛЬНОЙ ОСНОВЫ МИРА}

Аннотация:

Достижение мира между государствами - задача, исторически доказавшая всю сложность своей реализации. Ее осознание требует активных действий политических и государственных деятелей, общественных объединений и народов по предупреждению войн и вооруженных конфликтов, ликвидации причин и разрушения механизмов их возникновения. Такие выступления носят как организованный, так и стихийный характер. При этом стихийные выступления за мир и разоружение под влиянием тех или иных политических и общественных организаций, выступающих за безопасность и содружество народов, могут реализовываться во все более сознательное и организованное массовое движение. Они могут быть поддержаны миролюбивой политикой государств, ориентированных на жизненные интересы своих стран и всего человечества. Однако в результате непоследовательности, а порой недальновидности некоторых правительств и политических лидеров процесс борьбы за мир протекает сложно, противоречиво, сопровождается вооруженными конфликтами и напряженностью в отношениях между странами. В статье рассматривается проблема обеспечения мира через активную и возрастающую силу миротворческого процесса в лице таких субъектов, как мировое ученое сообщество, женские организации, различные экологические движения, религиозные объединения и др.

Ключевые слова:

общественные организации, международные организации, религиозные организации, социальная основа мира, глобальные проблемы, миротворческие процессы.

\section{Martynenko Elena Viktorovna}

D.Phil. in Political Science, Professor, Head of Journalism Theory and History Department, Philology Subdepartment,

Peoples' Friendship University of Russia

\section{PUBLIC ORGANIZATIONS IN THE SYSTEM OF WORLD SOCIAL BASIS}

Summary:

Keeping peace between the countries is a task that historically proved the complexity of its implementation. Its awareness requires the great efforts of political and public figures, public associations and peoples to prevent wars and armed conflicts, eliminate their causes and destroy their mechanisms. Such actions are both arranged and spontaneous. At the same time, the spontaneous standing for peace and disarmament under the influence of certain political and public organizations advocating for the security and commonwealth of peoples can lead to more conscious and arranged mass movement. It can be supported by a peaceful policy of states focused on the vital interests of their countries and humankind. However, because of the inconsistency and sometimes the shortsightedness of several governments and political leaders, the struggle for peace is a complex, contradictory process accompanied by the armed conflicts and tension among the countries. This study examines the issue of ensuring peace through the intensive and growing peacekeeping process via such actors as the world academic community, women's organizations, various environmental movements, religious associations.

Keywords: public organizations, international organizations, religious organizations, world social basis, global issues, peacekeeping processes.

Большое значение в социальной основе мира имеют представители науки, ученые различных отраслей знаний. Современные деятели науки в борьбе за мир в значительной степени опираются на гуманистическую традицию тех ученых, которые в середине XX столетия активно выступали против ядерной войны, провозглашали идеи безопасности и сотрудничества между государствами. Это прежде всего Н. Бор, А. Эйнштейн, Б. Рассел, Ф. Жолио-Кюри, Л. Полинг, П. Бриджмен и др. «Мы должны научиться мыслить по-новому, - отмечалось в Манифесте Рассела - Эйнштейна. - Мы должны научиться спрашивать себя не о том, какие шаги надо предпринять для достижения военной победы лагеря, к которому принадлежим, ибо таких шагов больше не существует; мы должны задать себе следующий вопрос: какие шаги можно предпринять для предупреждения вооруженной борьбы, исход которой должен быть катастрофическим для всех ее участников» [1]. И такие выступления известных ученых в борьбе за мир вполне обоснованы, поскольку именно они знают, чем чреваты для цивилизации гонка вооружений, распространение ядерного оружия и оружия массового поражения на планете.

Характерно, что в ряды активных борцов мира в наше время входят те, кто в прошлом являлись видными сторонниками применения в войне ядерного оружия. Так, известный в прошлом теоретик ограниченной ядерной войны Ч. Осгуд после выступал против нее, ратовал за укрепление 
безопасности в мире, развитие мер доверия между народами. Он заявлял: «Сохранение мира является величайшей проблемой нашего времени. Я уверен, что политика поэтапного снятия напряженности может быть осуществлена. Такая политика смогла бы повысить стабильность в военной обстановке и, быть может, создать атмосферу, в которой могут бы предприняты более значительные шаги к разоружению, а на длительный срок может быть предложена модель международных отношений, которая будет соответствовать следующему веку ядерной технологии» [2, p. 293].

Следует заметить, что движение ученых, несмотря на отсутствие у них рычагов воздействия и политических полномочий принимать решения в области борьбы за мир, обладает немалыми возможностями в гуманистическом процессе сохранения цивилизации. Декларации, решения, резолюции, воззвания и иные документы международных научных форумов оказывают значительное воздействие на общественное сознание, формирование международной солидарности и духе мира и сотрудничества народов.

Наряду с зарубежными исследователями, такими как Карл Саган и Стивен Шнейдер, отечественные ученые Никита Моисеев и Владимир Александров разработали математическую модель глобальных биосферных процессов. Она дала возможность весьма полно представить климатические последствия ядерной войны. Существовавшие ранее представления о возможности всеобщей гибели были подтверждены математическими расчетами. Ученые доказали, что «ядерная зима» наступит даже при локальном конфликте. Радиация, отсутствие воды и пищи, холод, психологический стресс и т. п. приведут к гибели всего живого на Земле.

Нельзя не отметить, что в дело укрепления мира вносят вклад и национальные отряды ученых, в том числе США, России, Франции и других государств. Так, видные представители науки в США Х. Бете, Л. Полинг, Г. Йорк, Дж. Стоун и другие создали весьма работоспособную научную организацию - «Союз обеспокоенных ученых». Своим авторитетом она вносит значительный вклад в формирование общественного мнения против гонки вооружений. Так, находясь у истоков этого Союза, Х. Бете отмечал: «Убеждение в том, что в изменяющемся мире мы должны изменить политику, разделяется многими группами и отдельными лицами. Все ныне прямо или косвенно говорит о том, что ядерные боевые головки не должны служить военным целям» [3, р. 17].

Движение подобного характера наряду с США развивается и в государствах Европы. В Англии, например, активно действует комитет ученых по вопросу снятия военной напряженности, гонки вооружений, развития мер безопасности. К числу таких ученых относятся: лауреат Нобелевской премии Д. Ходжкин, ведущий астрофизик М. Райл, професcор Р. Хайд.

Во Франции, опираясь на идеи Ф. Жолио-Кюри, ученые активно выступают в качестве сторонников исключения военной силы в международных отношениях. Так, известный французский исследователь из Тулузского университета Л. Мандевиль отмечал: «Развертывающиеся в мире политические процессы требуют пересмотра тех подходов во взаимоотношениях между странами и народами, которые были характерны для периода холодной войны. Они должны быть основаны на взаимном доверии государств» [4, р. 81].

Значительную работу по укреплению мира и взаимопонимания народов проводит научная общественность России. Отечественные ученые, среди которых Ж. Алферов, Ю. Осипов, Н. Моисеев, В. Басов, Д. Лихачев, Д. Сахаров и др., опираясь на преемственность традиций, активно развивали идеи по вопросу безопасности человечества, провозглашенные в 80-Х гг. XX в. Научным советом по исследованию проблем мира и разоружения Академии наук СССР. Российские ученые организуют и проводят международные встречи и симпозиумы, обеспечивают сотрудничество с исследовательскими институтами и центрами различных стран, инициируют конференции и дискуссии по вопросам разоружения, безопасности и укрепления мира. В рамках российского научноэкспертного сообщества существует Российский совет по международным делам (РСМД), который занимается системным анализом международных отношений, а также принимает участие в организации как внутрироссийских, так и международных семинаров по указанной проблематике.

Значительную роль в борьбе за взаимопонимание народов играет международное движение «Врачи мира за предотвращение ядерной войны». Возникнув в начале 80-х гг. прошлого столетия на встрече американских и советских ученых-медиков, движение врачей стало авторитетным субъектом в укреплении мира между государствами, а также массовыми общественными организациями. Достаточно сказать, что национальные комитеты движения активно работают почти в шестидесяти странах. При этом само движение объединяет медиков с далеко не идентичными политическими убеждениями и мировоззренческими установками.

На одном из конгрессов движения врачей, состоявшемся в Амстердаме (1983) и проходившем под девизом «Ядерные иллюзии - чем расплачивается человечество», было предложено дополнить клятву Гиппократа словами: «Как врач..., сознающий, что ядерное оружие представляет собой беспрецедентный вызов моей профессии, что ядерная война будет последней эпидемией для человечества, я сделаю все, что в моих силах, во имя предотвращения ядерной 
войны» [5, с. 225]. Врачи мира в своих взглядах опираются на положение о том, что единственным весомым аргументом против катастрофических последствий ядерной войны может быть только прекращение гонки вооружений, снижение порога ядерного противостояния.

Активными участниками международного движения сторонников мира являются объединения женщин, их организации. В настоящее время международное женское движение «За мир» (МЖДМ) объединяет в своих рядах многочисленные организации из почти 130 стран планеты. Ими последовательно проводятся крупные форумы, на которых активно обсуждаются актуальные проблемы состояния мира, предотвращения вооруженных конфликтов, снижения бремени гонки вооружений, раскрываются перспективы укрепления сотрудничества народов в экономике, политике и культуре.

В настоящее время в России действует Общероссийская ассоциация женских общественных организаций «Консорциум женских неправительственных объединений», которая эффективно работает как на местном, так и на федеральном уровнях. Реализуется одна из превентивных информационных сетей раннего предупреждения социальных конфликтов, ведущих к нарушению стабильности в регионах. С этой целью созданы узловые пункты (их более 120), информация из которых поступает и обрабатывается в едином аналитическом центре. Использование деятельности Консорциума женских неправительственных объединений обусловлено психологическими особенностями женщин: любознательностью, терпимостью, доброжелательностью. Например, благодаря работе женских организаций можно избежать вмешательства армии или внутренних войск в тех случаях, когда ситуация разрешима без использования силы.

Также в России активно действует межрегиональная женская общественная организация «Конверсия и женщины», которая уделяет большое внимание проблеме безопасности, укреплению мира.

Нельзя игнорировать участие женщин-военнослужащих в миротворческих операциях сил ООН. Так, совместными действиями женщин, входящих в командный состав миротворческих сил, и женщин, работающих в НПО, была проведена подготовка к выборам в Южной Африке, благодаря которой не понадобилось привлекать военный контингент при их осуществлении. Участие женщин способствует снятию социальной напряженности, блокировке потенциальных вооруженных конфликтов в ходе избирательной кампании со стороны местного населения. Женщины, принимающие участие в мирных переговорах, выполняют свою работу терпеливо, умеют выслушивать противоположные стороны, вносят в атмосферу переговоров дух доверия, дипломатично разрешают противоречия между полярными группами, предлагают нестандартные решения. Например, еще в 1993 г. в операциях ООН в Западной Сахаре женщины-военнослужащие составляли 10,2 \% общей численности войск. Характерно, что согласно резолюции Генеральной Ассамблеи ООН (№ 49/667) предполагается достичь 50 \%-го гендерного баланса в войсках ООН.

Участие женщин в разработке и применении превентивных мер в сфере безопасности приводит к выводу о необходимости соблюдения гендерного баланса во всех сферах жизни общества, включая и проблемы войны и мира [6, с. 150, 152].

Борьба за мир и выживание человечества объективно требует от всех народов и общественных организаций совместных усилий в решении глобальных проблем. К наиболее значительным из них относятся: энергетическая, охрана окружающей среды, борьба с голодом и болезнями, мирное освоение космического пространства и др. Подсчеты ученых свидетельствуют, что под угрозой существования находится биосфера и ее основные компоненты. Тревожно, что такая негативная тенденция не ослабевает в третьем тысячелетии. Так, на начало XXI в. интенсивность жизни в Мировом океане упала на $30 \%$. Биомасса суши уменьшилась на $7 \%$, а ее продуктивность на $20 \%$. Под угрозой исчезновения находятся до 10 \% видов растений и 30 \% видов животных [7, с. 86-87]. Особое беспокойство ученых в современной экологической ситуации вызывает развитие в глобальном масштабе условий для стимулирования «парникового эффекта», что ведет к быстрому повышению температуры на планете, резкому усилению влагооборота между морской акваторией и континентами. «...2016 стал рекордно теплым годом. Средняя температура на $1,1^{\circ} \mathrm{C}$ выше прежнего рекорда в 2015 г. Повышение глобальной температуры согласуется с другими изменениями в климатической системе. Средний уровень температуры поверхности моря стал самым теплым за время изучений; уровень океана продолжает расти; массивы льда арктических морей существенно понизились по сравнению с прежними годами» [8]. Это способно привести к разрушению прибрежных льдов Арктики и Антарктики, повышению уровня Мирового океана на 5-6 м.

Нарастание опасности климатической катастрофы ставит все страны и народы планеты, независимо от государственно-политических, культурных и национально-этнических различий, перед неотложной необходимостью дальнейшей разработки и срочной реализации актуальных идей глобальной стратегии активной борьбы за сохранение и развитие экологических основ существования человечества. На это обстоятельство еще в конце XX в. обращал внимание академик Никита Моисеев. «Вопросы планетарной экологии, - отмечал он, - не только во все большей 
степени занимают внимание ученых и политиков, но ставятся предметом общего интереса всех образованных людей» [9, с. 160].

В наше время возрастает опасность постепенного движения планеты в сторону «тихой» биохимической и генетической деградации. Это обусловлено радиоактивно-токсическим загрязнением окружающей среды в результате деятельности людей. Трагизм ситуации заключается в том, что отравление биосферы уже сейчас представляет реальную угрозу здоровью и жизни человека на Земле. Так, исследования академика Николая Дубинина свидетельствуют, что в различных странах мира уже пострадали миллионы людей, дети которых родились с генетическими отклонениями.

Вместе с тем следует подчеркнуть один важный аспект. Он связан с тем, что экологическая и военная опасность тесно взаимодействуют друг с другом. Это выражается как в угрозе человечеству глобальным уничтожением, так и в преодолении этих опасностей. Экологическая проблема столь масштабна и дорогостояща, что сколько-нибудь основательное решение ее возможно при отвлечении материальных и финансовых ресурсов, приходящихся на гонку вооружений. Ныне мировые военные расходы составляют примерно 1686 млрд долл. в год [10], тогда как каждый седьмой человек в мире голодает [11].

Современная глобальная ситуация, проявляющаяся в военной и экологической опасности, превратила концепцию мира для всех народов в категорический императив стран планеты. Реальности нашего времени свидетельствуют о том, что важной институционной базой обсуждения и решения глобальных проблем являются международные организации. Это в первую очередь относится к ООН, включающей как общие по своим функциям, так и специализированные организации. Прежде всего те, компетенция которых совпадает или в значительной мере схожа с той или иной глобальной проблематикой (ФАО - продовольствие, ЮНЕП - охрана среды и т. д.).

Решение глобальных проблем с позиции заинтересованности государств в мире невозможно без изменения международных отношений. А оно, на наш взгляд, требует учета следующих особенностей развития современного мира. Во-первых, решение глобальных проблем происходит при существовании в мире разного уровня развития экономических систем в тех или иных государствах. Это требует от их руководителей взаимной терпимости и внимания к каждому из них и поиска направлений применения совместных усилий. Во-вторых, изучение глобальных проблем показывает, что они взаимосвязаны. Усилия по решению каждой из них требуют координации. Так, бережное освоение ресурсов Мирового океана может внести значительный вклад в улучшение энергетической и продовольственной ситуации на Земле. В-третьих, планетарные усилия в сфере глобальных проблем предполагают учет специфических условий развивающихся стран. Это связано с тем, что проблемы (продовольственная, демографическая, борьба с болезнями) стоят в развивающихся странах весьма остро. В то же время именно в таких странах во многом заложены резервы расширения материальной основы для энергетической, сырьевой и продовольственной проблемы.

В условиях современного состояния духовной жизни общества, противоречивых процессов общественного развития, осмысления проблемы войны и мира значительную роль играет религия.

Религия все активнее выступает в качестве сторонника мира в силу ряда обстоятельств. Во-первых, ее поддерживают в стремлении и укреплении мира широкие массы простых верующих во всех частях планеты, принимающие участие в борьбе за демократию, гуманизм, предотвращение войны и укрепление безопасности между народами и государствами. Степень осознания ими своих жизненных интересов определяет конкретное выражение деятельности различных конфессий за мир.

Во-вторых, «поворот к миру» осуществляют те религиозные деятели, теологи и священнослужители, которые, осознавая гуманистические устремления части верующих, стремятся внести специфический религиозный вклад в общественный прогресс. Возрастающий реализм и понимание ответственности перед миром соединяются у них с ясно выраженным стремлением путем реформы религии повысить ее привлекательность, противодействовать усилившейся секуляризации.

В-третьих, выступление различных религиозных конфессий в пользу мира за последние годы обусловлено пониманием жизненной необходимости мирного сосуществования как для народов, так и для самих руководителей религиозных организаций и объединений. Следует заметить, что руководители христианства уже в 70-х гг. XX столетия давали ориентацию верующим массам для практических и действенных акций за мир. Линия конкретного и решительного выступления за мир и превращения дела мира в общественное дело была разносторонне раскрыта папой римским Павлом VI, который был первым среди руководителей Ватикана, сделавшим на заседании Генеральной Ассамблеи ООН (1965) программное заявление в пользу мира.

В современных общественно-политических условиях религии свойственны особенности, связанные с ее воздействием на миротворческий процесс. Обратим внимание на наиболее важные из них. 
Особенность первая (основание по масштабу). Религиозные выступления за мир получают всеобъемлющий, международный характер. Специально по вопросу мира религиозные сообщества сотрудничают на международном уровне, значительные христианские миролюбивые движения организованы в международном масштабе.

Экуменические органы, выступающие за мир на международном и региональном уровне, разрабатывают концепции и действуют в качестве организующей силы, оказывая влияние на отдельные религиозные сообщества, обращаются с воззваниями к политическим деятелям и мировой общественности. Проводятся встречи, консультации и конференции представителей различных вероисповеданий, а в рамках одного вероисповедания - между отдельными странами. Кроме того, устанавливается сотрудничество с другими религиями. Представители религиозных сообществ и миролюбивых движений встречаются с религиозными руководителями и миролюбивыми организациями других религий для обсуждения совместных действий, например, по борьбе с международным терроризмом [12].

Особенность вторая (основание по субъекту). Миролюбивые акции религиозных сил осуществляются уже не отдельными представителями, а рядом движений или групп; не разрозненными пацифистскими религиозными общинами, а массой верующих, влиятельными религиозными движениями за мир и религиозными организациями, преданными идеям мира.

Вместе с тем религиозные выступления за мир понимаются в целом не как обособленное движение за мир со своими религиозными целями, а как часть более широкого движения. Миролюбивые религиозные силы в настоящее время нередко предстают как сторонники общегуманитарного движения за мир. Многие представители религиозных организаций обращаются в своих воззваниях не только к верующим, но и ко всем людям доброй воли, будучи готовы сотрудничать с ними. Религиозные миролюбивые движения частично обладают статусом неправительственных учреждений в ООН и имеют своих представителей в ООН и ее организациях.

Особенность третья (основание по содержанию). Миролюбивые выступления религиозных организаций основываются на политических представлениях и общечеловеческих морально-этических постулатах без ущерба для различных конфессий и их теоретических положений. В последние годы ими делается сознательная ставка на морально-этические положения в целях оптимизации сотрудничества с нерелигиозными миролюбивыми силами.

Главное этическое требование религиозных миролюбивых сил сводится к признанию человеческой жизни высшей ценностью в реальном мире («благоговение перед жизнью» как величайшим творением Бога). Их главное политическое требование заключается в запрещении ядерной войны и всех средств, которые могли бы ее вызвать, в частности гонки вооружений, создания новых, еще более губительных для человека вооружений и военно-политических доктрин.

Особенность четвертая (основание по связи). Религиозные миролюбивые силы признают и используют результаты различных отраслей науки и в общем не выдвигают притязаний на особое познание конкретных проблем обеспечения мира. Они не отказываются от точки зрения, согласно которой проблема мира в конечном счете выступает в качестве проблемы «грешного мира» и окончательно может быть решена только путем обращения человека к богу. В этой связи религиозные миролюбивые силы ставят на первый план требование «разумного» выступления за мир, которое учитывает реальные политические и военные условия обеспечения мира.

Наряду с этим аспектом религиозные организации рассматривают создание миролюбивой цивилизации в связи с необходимостью формирования у людей понимания «справедливого мира». А это означает широкое осмысление верующими и неверующими таких вопросов, как народное экономическое устройство; преодоление угнетения, нищеты, голода и неграмотности; милосердие в международных отношениях. Наконец, они выступают за использование науки и техники для развития и обогащения человеческой жизни, за такое отношение к естественным, природным ресурсам Земли, которое обеспечит подобающую жизнь будущим поколениям.

Обобщая вышесказанное, отметим, что современная социальная основа обеспечения мира в немалой степени отличается от ее аналогов в прошлом. В наше время проблема обеспечения прочного мира во все большей степени реализуется через деятельность общественных и религиозных организаций. Современные реалии подтверждают активную и возрастающую силу миротворческого процесса в лице таких ее субъектов, как мировое ученое сообщество, женские организации, различные экологические движения, религиозные объединения и др. Проводя различного рода конференции, симпозиумы, круглые столы и т. п. по вопросам войны и мира, они приковывают внимание к ним широкой общественности, побуждают государственные институты принимать адекватные меры.

\section{Ссылки:}

1. Манифест Рассела - Эйнштейна // Дружба народов. 1988. № 6. С. 185. 
2. Osgood D. Graduated Unilateral Initiatives for Peace // The Arms Race and Nuclear War / ed. by W.M. Evan, S. Hilgartner. New Jersey, 1987. P. 293.

3. Bethe H. The Situation Today: Nuclear Forces that Reflect War - Fighting Doctrine. New Jersey, 1987. P. 17

4. Mandeville L. Note sur la consistance et le poids da complexe militaro-industriel. Toulouse, 1994. P. 81.

5. Ц Цит. по: Капто А.С. Философия мира: истоки, тенденции, перспективы. М., 1990. С. 225.

6. См.: Банкова М.Б., Иванова Э.М. О взаимоотношениях армии и гражданского общества (роль женских НПО в вопросах политики безопасности) // Научный альманах высоких гуманитарных технологий. Специальный выпуск. М., 2000. C. $150-152$.

7. См.: Горелов А.А. Социальная экология. М., 1998. С. 86-87.

8. WMO Statement on the State of the Global Climate in 2016 [Электронный ресуpc]. URL: https://library.wmo.int/opac/doc num.php?explnum id=3414 (дата обращения: 14.11.2017).

9. Моисеев Н.Н. С мыслями о будущем России. М., 1997. С. 160.

10. Trends in World Military Expenditure, 2016 [Электронный ресурс] / N. Nian, A. Fleurant, P.D. Wezeman, S.T. Wezeman. URL: https://www.sipri.org/sites/default/files/Trends-world-military-expenditure-2016.pdf (дата обращения: 14.11.2017).

11. Развитие не может быть устойчивым, если каждый седьмой человек в мире голодает [Электронный ресурc]. URL: http://www.un.org/russian/news/story.asp?NewsID=17348\#.WfhZAHYquUk (дата обращения: 14.11.2017).

12. ОБСЕ приняла предложенную Россией декларацию по борьбе с терроризмом [Электронный ресурc]. URL: https://ria.ru/defense_safety/20151205/1336149644.html (дата обращения: 14.11.2017).

\section{References:}

Bankova, MB \& Ivanova, EM 2000, 'The relationship between the army and civil society (the role of female scientific production associations in security policy', Nauchnyy al'manakh vysokikh gumanitarnykh tekhnologiy. Spetsial'nyy vypusk, Moscow, pp. 150-152, (in Russian).

Bethe, H 1987, The Situation Today: Nuclear Forces that Reflect War-Fighting Doctrine, New Jersey, p. 17.

Gorelov, AA 1998, Social ecology, Moscow, pp. 86-87, (in Russian)

Kapto, AS 1990, Philosophy of the world: backgrounds, trends, prospects, Moscow, p. 225, (in Russian).

Mandeville, L 1994, Note sur la consistance et le poids da complexe militaro-industriel, Toulouse, p. 81, (in French).

Moiseev, NN 1997, Thoughts about the future of Russia, Moscow, p. 160, (in Russian).

Nian, N, Fleurant, A, Wezeman, PD \& Wezeman ST 2017, Trends in World Military Expenditure, viewed 14 November 2017, <https://www.sipri.org/sites/default/files/Trends-world-military-expenditure-2016.pdf>.

Osgood, D, Evan, WM \& Hilgartner, S (eds.) 1987, 'Graduated Unilateral Initiatives for Peace', The Arms Race and Nuclear War, New Jersey, p. 293

'The Russell-Einstein Manifesto' 1988, Druzhba narodov, no. 6, p. 185, (in Russian).

WMO Statement on the State of the Global Climate in 2016 2017, viewed 14 November 2017, <https://library.wmo.int/opac/doc_num.php?explnum_id=3414>. 